\title{
Stability and Aggregation Kinetics of Silver Nanoparticles in Water in Oil Microemulsions of Cetyltrimethylammonium Bromide and Triton X-100
}

\author{
F. Begum ${ }^{1}$, S. A. Jahan', M. Y. A. Mollah', M. M. Rahman ${ }^{3}$, M. A. B. H. $\operatorname{Susan}^{3} *$ \\ ${ }^{1}$ Institute of Glass and Ceramic Research and Testing, Bangladesh Council of Scientific and \\ Industrial Research, Dhaka, Bangladesh \\ ${ }^{2}$ University Grants Commission of Bangladesh, 29/1 Agargaon, Sher-E-Bangla Nagar, Dhaka-1207, \\ Bangladesh \\ ${ }^{3}$ Department of Chemistry, University of Dhaka, Dhaka-1000, Bangladesh
}

Received 8 June 2017, accepted in final revised form 10 September 2017

\begin{abstract}
Water in oil $(W / O)$ microemulsions are simple preparative route for nanoparticles where water droplets dispersed in oil stabilized by surfactant or surfactant and cosurfactant monolayer act as nanoreactors to carry out chemical reactions. In this work, silver nanoparticles (AgNPs) were prepared in $W / O$ microemulsions of cetyltrimethylammonium bromide (CTAB) and triton X-100 (TX-100) by using $\mathrm{AgNO}_{3}$ and $\mathrm{NaBH}_{4}$ as a precursor salt and reducing agent, respectively. To prepare microemulsions, CTAB or TX-100, 1-pentanol, cyclohexane and water were mixed with different molar ratio. AgNPs were prepared with different $\left[\mathrm{AgNO}_{3}\right]$ in microemulsions of $\mathrm{CTAB}$ with fixed water to surfactant ratio $\left(W_{\mathrm{o}}\right)$. Average particle sizes were determined from dynamic light scattering (DLS) measurements. AgNPs prepared from microemulsions of CTAB were unstable while from TX-100, NPs were stable. Aggregation kinetics was investigated by measuring the absorbance at definite time intervals at the absorption maximum, $\lambda_{\max }$ of AgNPs in different media under pseudo-first-order conditions. The aggregation behavior was studied at different $\left[\mathrm{AgNO}_{3}\right]:\left[\mathrm{NaBH}_{4}\right]$ and $W_{\mathrm{o}}$ and the parameters were optimized to ensure formation of stable AgNPs without aggregation in microemulsions. This would help tuning the size, stability, and aggregation kinetics of AgNPs by controlling the nature of the surfactant and composition of the microemulsions.
\end{abstract}

Keywords: Water in oil microemulsions; Particle size distribution; Stability and aggregation kinetics.

(C) 2017 JSR Publications. ISSN: 2070-0237 (Print); 2070-0245 (Online). All rights reserved. doi: http://dx.doi.org/10.3329/jsr.v9i4.32838 J. Sci. Res. 9 (4), 431-447 (2017)

\section{Introduction}

Nanoparticles (NPs) are of great scientific interest as they bridge the gap between bulk materials and atomic or molecular structures [1]. Among various NPs, silver nanoparticles

\footnotetext{
*Corresponding author: $\underline{\text { susan@du.ac.bd }}$
} 
(AgNPs) are the most promising ones. The physical and chemical properties of the AgNPs change with change in the size or surface of the NPs [2,3]. Good conductivity, optical properties, and chemical stability of AgNPs made them promising for a range of applications for instances, in industries as catalysts, in medical sciences to deal with HIV virus and in food industries as anti-bacterial agents for food packing, etc [4-10].

The usage of AgNPs more often becomes the concern for their toxicity at high concentrations. The production of goods containing AgNPs, in general, increases release to the environments with possible harmful effect on human beings [11,12]. Once released into the environment, AgNPs may bring environmental transformations which inter alia include: aggregation, sedimentation, oxidation, interaction with organic matter and pollutants. Thus, it is important to investigate factors that determine the stability and aggregation of AgNPs in addition to intrinsic properties like diameter, charge, shape, concentration and coating [13-16].

AgNPs prepared from aqueous media are often unstable and tend to aggregate [17, 18]. Different capping agents, for instances, polymers [19-22] and surfactants [4,23-25] or surfactant-based organized media such as; micelles [4], reverse micelles [26-32] and microemulsions [33-39] are in general used to stabilize the NPs. In particular, water in oil microemulsions $(W / O)$ ) are widely used to synthesize NPs with controllable shape and size and higher stability $[15,17,40]$. The capping agents usually form a coated layer on the surface of NPs which prevents auto-aggregation through electrostatic or steric repulsion or even both during the synthesis of NPs [41].

There are numerous reports in the literature on the preparation of AgNPs from microemulsions using a range of surfactants [33-39]. Surprisingly, stability and aggregation of AgNPs prepared from different $W / O$ microemulsions still remains an unsettled issue. In this work, we prepared AgNPs from microemulsions of a cationic surfactant, cetyltrimethylammonium bromide (CTAB) and a nonionic surfactant, triton X100 (TX-100) with different water to surfactant ratio $\left(W_{\mathrm{o}}\right)$. The stability and aggregation kinetics of prepared AgNPs have been studied in detail. The effects of ratio of $\mathrm{AgNO}_{3}$ with $\mathrm{NaBH}_{4}$ and $W_{\mathrm{o}}$ on stability and aggregation of AgNPs have been examined to find suitable means to prepare stable AgNPs avoiding aggregation.

\section{Materials and Methods}

\subsection{Chemicals}

Cetyltrimethylammonium bromide (CTAB) (E. Merck), triton X-100 (TX-100) (PAKARD), n-pentanol (JHD Chemical), cyclohexane $(\mathrm{BDH})$, silver nitrate $\left(\mathrm{AgNO}_{3}\right)$ $(\mathrm{BDH})$ and sodium borohydride $\left(\mathrm{NaBH}_{4}\right)$ (Across Organics) were each reagent grade material and used as received without further purification. 


\subsection{Preparation of water in oil microemulsions of CTAB and TX-100}

Water in oil $(W / O)$ microemulsions were prepared by mixing $10.0 \%$ wt. surfactant (for both CTAB and TX-100) with cyclohexane as the oil phase $(62.3 \%$ wt. and $83.0 \%$ wt. for CTAB and TX-100, respectively) followed by addition of water and $n$-pentanol to have clear microemulsions with varying water and $n$-pentanol contents. These microemulsions were prepared by using deionized double distilled water and the water to surfactant ratio $\left(W_{\mathrm{o}}\right)$ was maintained in the range of $3.90 \sim 20.0$. The required amount of CTAB/TX-100, $n$-pentanol, cyclohexane and water were added one after another in a vial and sonicated to prepare clear $W / O$ microemulsions.

\subsection{Preparation and characterization of AgNPs}

Aqueous $\mathrm{AgNO}_{3}$ solution and $\mathrm{NaBH}_{4}$ were used, respectively, as a metal salt precursor and a reducing agent for the preparation of AgNPs. The characteristic pale yellow color after the addition of $\mathrm{NaBH}_{4}$ solution indicated the formation of AgNPs in aqueous solution.

AgNPs were synthesized using double microemulsions reactant addition method. 2 $\mathrm{mL}$ of two microemulsions, one solubilized with $\mathrm{AgNO}_{3}$ and the another with $\mathrm{NaBH}_{4}$ as the reducing agent were mixed and sonicated for about $30 \mathrm{~min}$. An immediate color change; from colorless to golden yellow solution indicated the formation of AgNPs [17].

The optical absorption spectra for AgNPs in water and microemulsions with different surfactants were recorded using a double beam Shimadzu UV-visible spectrophotometer, UV-1800. Rectangular quartz cells of path length $1 \mathrm{~cm}$ were used throughout the investigation. Size and size distribution of the AgNPs synthesized in water and the water pools of the W/O microemulsion were measured using a Zetasizer Nano ZS90 (ZEN3690, Malvern Instruments Ltd., UK) using dynamic light scattering method (DLS) method. The particle size detection limit was about $0.3 \mathrm{~nm}-5 \mu \mathrm{m}$ (diameter) and accuracy of the average diameter determined has been $\pm 2 \%$. A He-Ne laser beam of $632.8 \mathrm{~nm}$ wavelength was used and the measurements were made at a fixed scattering angle of $90^{\circ}$. The average diameters were determined from cumulants mean of the intensity average of 50 runs using Stokes-Einstein equation, $R_{\mathrm{h}}=k T / 6 \pi \eta D_{\text {eff }}$, where $R_{\mathrm{h}}$ is hydrodynamic radius, $k$ is the Boltzmann constant, $T$ is the temperature, $\eta$ is the solvent viscosity, and $D_{\text {eff }}$ represents the diffusion coefficient. The reproducibility was checked from at least 3 measurements. The temperature of the apparatus was controlled automatically within $\pm 0.01 \mathrm{~K}$ by a built-in Peltier device.

\subsection{Kinetic study}

The rate of the formation/aggregation AgNPs was measured by solubilizing appropriate amount of $\mathrm{AgNO}_{3}$ in water or W/O microemulsions of CTAB or TX-100 and adding calculated amount of $\mathrm{NaBH}_{4}$ solution $\left(\left[\mathrm{NaBH}_{4}\right] \gg\left[\mathrm{AgNO}_{3}\right]\right)$. The progress of the reaction was followed spectrophotometrically by pipetting out aliquots at definite time 
intervals and measuring the absorbance of silver sol formed at the absorption maximum, $\lambda_{\max }$ corresponding to the pale-yellow color. Water or microemulsion containing all the constituents except $\mathrm{AgNO}_{3}$ and $\mathrm{NaBH}_{4}$ was used as the reference. In the cases of kinetic measurements, absorbance at the $\lambda_{\max }$ of AgNPs in microemulsions of CTAB/TX-100 was monitored since the $\lambda_{\max }$ was found to shift slightly in these media compared to that in water. Replicate measurements gave results that were reproducible within $\pm 4 \%$. The apparent rate constants $\left(k_{\mathrm{obs}}, \mathrm{s}^{-1}\right)$ were calculated from the slopes of the semilogarithimc plots of concentration and time [42].

\section{Results and Discussion}

\subsection{Formation/aggregation and characterization of AgNPs in water}

The AgNPs were prepared from water following the procedure described by Solomon et al [17]. The stable yellow AgNPs could be prepared from water by controlling reaction conditions including stirring time and relative amounts of reagents. Upon continuous stirring for $2 \mathrm{~h}$ after the addition of all $\mathrm{AgNO}_{3}$, the color of the solution did not show appreciable change indicating stability of AgNPs. In contrast, after 10 days, darker yellow solution turned into grayish solution due to aggregation of AgNPs (vide infra).

\subsubsection{Characterization}

AgNPs showed yellowish brown color in water due to excitation of surface plasmon resonance band in the UV-visible region or interband transition of AgNPs [43, 44]. The $\mathrm{UV}-\mathrm{V}$ is spectroscopy could therefore be used to examine size and shape of the AgNPs. Fig. 1 represents the UV-visible spectra of synthesized AgNPs stirring at $40 \mathrm{~min}$ and $2 \mathrm{~h}$ more after the formation of AgNPs.

The absorption spectra of AgNPs in aqueous solution consist of a single sharp surface plasmon resonance band at $395 \mathrm{~nm}$ (Fig. 1). The most characteristic part of silver sol is a narrow plasmon absorption band observable in the 350-600 nm regions. A broad surface plasmon resonance band is due to aggregation of AgNPs. The wavelength of the plasmon absorption maximum in a given solvent can be used to indicate particle size [45]. The value of the peak width at half maximum (PWHM) for freshly prepared AgNPs are 67 and $70 \mathrm{~nm}$ for AgNPs stirred at $40 \mathrm{~min}$ and $2 \mathrm{~h} 40 \mathrm{~min}$, respectively. After 10 days the value of the absorption maximum changes from 395 to 410 and $405 \mathrm{~nm}$ for AgNPs stirred for 40 min and $2 \mathrm{~h} 40 \mathrm{~min}$, respectively. The corresponding values of PWHM of freshly prepared AgNPs and 10 days after preparation stirred at $40 \mathrm{~min}$ and $2 \mathrm{~h} 40 \mathrm{~min}$ are listed in Table 1. 


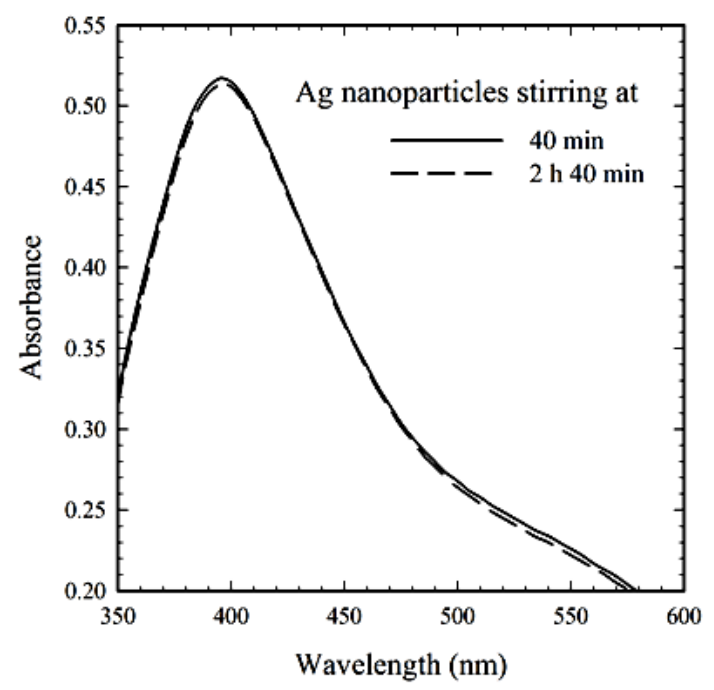

Fig. 1. UV-visible spectra of synthesized AgNPs in aqueous solution stirring at $40 \mathrm{~min}$ and $2 \mathrm{~h}$ more after the formation of AgNPs.

Table 1. Peak width at half maximum (PWHM) of AgNPs.

\begin{tabular}{lll}
\hline AgNPs & Time of Stirring & PWHM (nm) \\
\hline Freshly prepared & 40 min & 67 \\
& $2 \mathrm{~h} 40$ min & 70 \\
After 10 days & 40 min & 112 \\
& $2 \mathrm{~h} 40 \mathrm{~min}$ & 97 \\
\hline
\end{tabular}

\subsubsection{Particle size of AgNPs}

Particle sizes of the prepared AgNPs were determined by DLS method. Table 2 represents sizes of freshly prepared AgNPs with their scattering intensity, polydispersity index (PDI) and standard deviations (Std. Dev.) for NPs stirred for $40 \mathrm{~min}$.

From Table 2, it is apparent that, the Z-Average diameters of freshly prepared AgNPs are lower than those for particles after 10 days of preparation to indicate aggregation of AgNPs. Size distribution shows bimodal and trimodal distributions for freshly prepared AgNPs and those after 10 days of preparation. The $\%$ intensity indicates that the amount of larger NPs is more than the smaller one. The PDI value suggests that the AgNPs prepared from water are polydispersed with broader size distribution: aggregation for a prolonged period for instance, after 10 days of preparation gives rise to larger aggregates of different sizes. 
Table 2. Size for AgNPs stirred for $40 \mathrm{~min}$.

\begin{tabular}{llllll}
\hline AgNPs & $\begin{array}{l}\text { Size of NPs } \\
(\mathrm{nm})\end{array}$ & $\begin{array}{l}\text { Z-average } \\
\text { Diameter }(\mathrm{nm})\end{array}$ & \% Intensity & Std. Dev. & PDI $^{1}$ \\
\hline Freshly & 68 & 17 & 77.7 & 52.94 & 0.679 \\
prepared & 3 & 22.3 & 1.28 & \\
\hline \multirow{2}{*}{$\begin{array}{l}\text { After 10 days } \\
\text { of preparation }\end{array}$} & 125 & 75 & 93.2 & 71.30 & \\
& 5 & & 3.2 & 1.35 & 0.427 \\
\hline
\end{tabular}

${ }^{1}$ The PDI, a width parameter, has been calculated from a Cumulants analysis of the DLS measured intensity autocorrelation function. In general, values smaller than 0.1 indicate reasonably narrow distribution and values greater than 0.7 indicate that the sample has a very broad size distribution.

\subsection{Formation/aggregation and characterization of AgNPs in W/O microemulsions of CTAB}

The formation of AgNPs in microemulsion could be visually observed from characteristic color change from colorless to golden yellow in the microemulsions [17,46,47] and therefore UV-visible spectral analysis could be used for the study of formation and aggregation behavior in microemulsions.

\subsubsection{Effect of concentration of $\mathrm{AgNO}_{3}$ on formation of $\mathrm{AgNPs}$}

AgNPs were prepared by using different concentrations of precursor salt. The concentration of $\mathrm{AgNO}_{3}$ was varied from 0.065 to $0.65 \mathrm{mM}$ for a fixed concentration (15 $\mathrm{mM}$ ) of $\mathrm{NaBH}_{4}$. With increasing the $\left[\mathrm{AgNO}_{3}\right]$, the color of AgNPs changes from light yellow to yellow to darker yellow, which could be observed by visual inspection. Fig.2 represents UV-visible spectra of AgNPs prepared by using different $\left[\mathrm{AgNO}_{3}\right]$ with a fixed concentration of $\mathrm{NaBH}_{4}$ from microemulsions of CTAB $\left(W_{\mathrm{o}}=7.10\right)$.

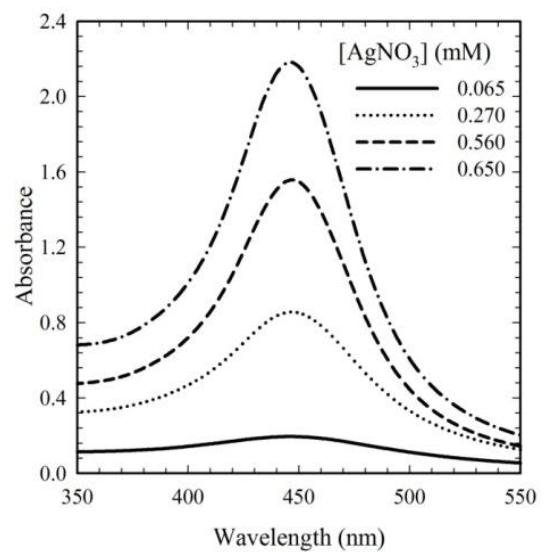

Fig. 2. UV-visible spectra of AgNPs prepared by using different $\left[\mathrm{AgNO}_{3}\right]$ with a fixed concentration $(=15 \mathrm{mM})$ of $\mathrm{NaBH}_{4}$. 
The absorption intensity increases with increase in $\left[\mathrm{AgNO}_{3}\right]$ increases to suggest formation of more AgNPs. Table 3 represents concentration and PWHM values of AgNPs with increasing $\left[\mathrm{AgNO}_{3}\right]$.

Table 3. Concentrations and PWHM values of AgNPs with increasing $\left[\mathrm{AgNO}_{3}\right]$.

\begin{tabular}{lll}
\hline $\begin{array}{l}{[\mathrm{AgNO}} \\
(\mathrm{mM})\end{array}$ & $\begin{array}{l}\text { Concentration of } \\
\text { AgNPs }(\mu \mathrm{L} / \mathrm{mL})\end{array}$ & PWHM \\
\hline 0.14 & 7.45 & 83 \\
0.54 & 29.12 & 63 \\
1.13 & 60.91 & 56 \\
1.30 & 70.00 & 50 \\
\hline
\end{tabular}

It is interesting to note a considerable amount of large particles (Table 3) at lower $\left[\mathrm{AgNO}_{3}\right]$. At higher $\left[\mathrm{AgNO}_{3}\right]$ on the other hand, there were substantial amount of smaller AgNPs which is indicative of a faster nucleation of the AgNPs. Small AgNPs with a high specific surface area could be formed in a short formed which is in good agreement with literature [48].

\subsubsection{Effect of $\mathrm{AgNO}_{3}: \mathrm{NaBH}_{4}$ on formation of $\mathrm{AgNPs}$}

Table 4 represents the PWHM values of AgNPs prepared by using different $\left[\mathrm{AgNO}_{3}\right]:\left[\mathrm{NaBH}_{4}\right](1: 6$ to $1: 30.8)$ after 5 min stirring. Small AgNPs were observed for $\left[\mathrm{AgNO}_{3}\right]:\left[\mathrm{NaBH}_{4}\right]=1: 10.8$.

Table 4. The PWHM values of AgNPs prepared by using different $\left[\mathrm{AgNO}_{3}\right]$ : $\left[\mathrm{NaBH}_{4}\right]$.

\begin{tabular}{ll}
\hline$\left[\mathrm{AgNO}_{3}\right]:\left[\mathrm{NaBH}_{4}\right]$ & PWHM \\
\hline $1: 6$ & 52 \\
$1: 10.8$ & 52 \\
$1: 23.1$ & 55 \\
$1: 30.8$ & 56 \\
\hline
\end{tabular}

\subsection{Stability and aggregation of AgNPs in water and W/O microemulsions of CTAB}

The absorption spectrum of AgNPs changes due to transition from a well-dispersed state to an aggregated state. Fig. 3 shows the change of absorbance at $395 \mathrm{~nm}$ with increasing time during the formation of AgNPs from water and $W / O$ microemulsions of $\mathrm{CTAB}\left(W_{\mathrm{o}}=\right.$ 7.10) with $\left[\mathrm{AgNO}_{3}\right]:\left[\mathrm{NaBH}_{4}\right]=1: 6$.

The absorbance vs time profile in Fig. 3 shows an increase in absorbance (up to 55 60 min for water and 10 15 min for microemulsion of CTAB $\left(W_{\mathrm{o}}=7.10\right)$ ) followed by decrease with increasing time. The increase in absorbance indicates an increase in the no. of AgNPs due to faster nucleation; while decrease in absorbance with time corresponds to 
formation of aggregates. The final aggregated state is visually observed since the original dispersed particles form a yellow solution and the aggregated particles become grey.

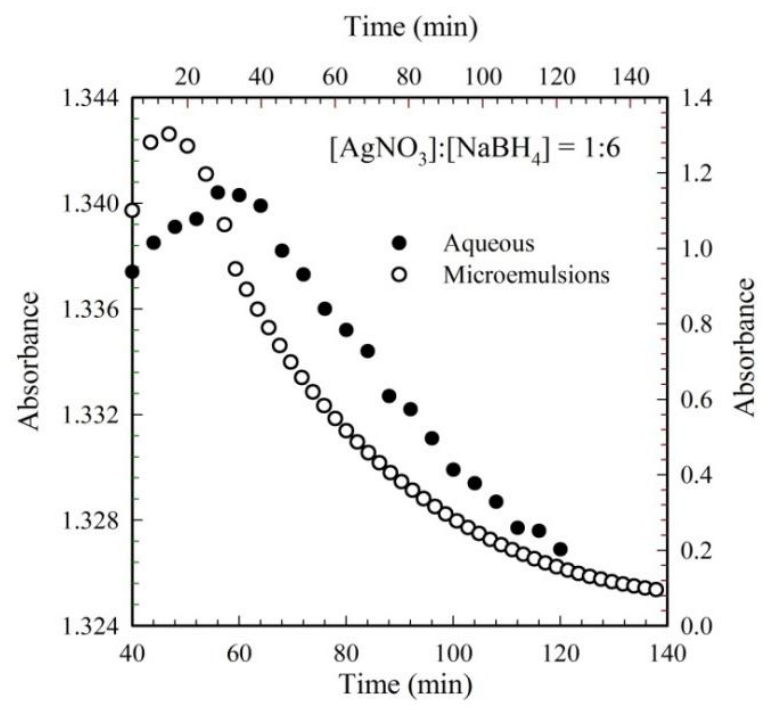

Fig. 3. Absorbance at $395 \mathrm{~nm}$ as a function of time during the formation of AgNPs from water and W/O microemulsions of $\mathrm{CTAB}$ with $\mathrm{AgNO}_{3}: \mathrm{NaBH}_{4}=1: 6$. Absorbance in the left corresponds to that for aqueous solution and in the right for microemulsions.

AgNPs prepared from microemulsions of CTAB $\left(W_{\mathrm{o}}=7.10\right)$ were unstable and precipitated out after 1 3 days depending on the $\left[\mathrm{AgNO}_{3}\right]$. For instance, the AgNPs prepared from $0.56 \mathrm{mM}$ of $\mathrm{AgNO}_{3}$ with $\left[\mathrm{AgNO}_{3}\right]:\left[\mathrm{NaBH}_{4}\right]=1: 23.1$ aggregated and precipitated out into the bulk after 1 day. This may be due to the facts that (i) a large no. of Ag atoms are available for the growth of nucleated particles to form larger AgNPs and (ii) collision frequency of the formed AgNPs increase significantly with $\left[\mathrm{AgNO}_{3}\right]$ [48]. Thus, AgNPs are easy to aggregate into larger ones at high $\left[\mathrm{AgNO}_{3}\right]$ at short time compared to low $\left[\mathrm{AgNO}_{3}\right]$.

\subsubsection{Effect of $\left[\mathrm{AgNO}_{3}\right]:\left[\mathrm{NaBH}_{4}\right]$ on stability and aggregation of AgNPs}

AgNPs have also been prepared by changing $\left[\mathrm{AgNO}_{3}\right]:\left[\mathrm{NaBH}_{4}\right]$ (from 1:10.8 to $1: 30.8$ ) from microemulsions of $\mathrm{CTAB}\left(W_{\mathrm{o}}=7.10\right)$ to study the effect of the strong reducing agent, $\mathrm{NaBH}_{4}$ on the stability and aggregation. The stability and aggregation of AgNPs were measured by monitoring the change of absorbance at $445 \mathrm{~nm}\left(\lambda_{\max }\right)$ with time. Fig. 4 represents the absorbance vs time profile for AgNPs with different $\left[\mathrm{AgNO}_{3}\right]:\left[\mathrm{NaBH}_{4}\right]$ in microemulsions of CTAB $\left(W_{\mathrm{o}}=7.10\right)$.

It is apparent from Fig. 4 that the absorbance increases until $\sim 10$ min and remains constant up to $\sim 30 \mathrm{~min}$ and then decreases. The AgNPs are stable for $\sim 15-20 \mathrm{~min}$ and aggregation starts after $\sim 30 \mathrm{~min}$ for all $\left[\mathrm{AgNO}_{3}\right]:\left[\mathrm{NaBH}_{4}\right]$. 


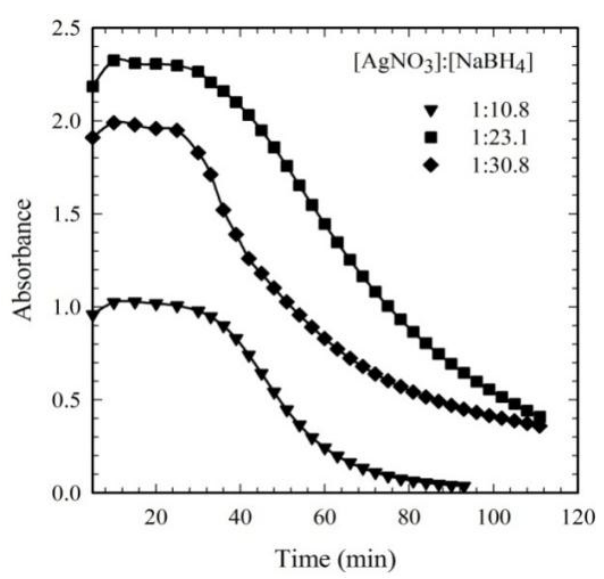

Fig. 4. Absorbance vs time profile for AgNPs with different $\left[\mathrm{AgNO}_{3}\right]:\left[\mathrm{NaBH}_{4}\right]$ in microemulsions of CTAB $\left(W_{\mathrm{o}}=7.10\right)$.

\subsubsection{Aggregation kinetics of AgNPs}

Stability and aggregation kinetics have been studied by measuring the absorbance at definite time intervals at $\lambda_{\max }$ of AgNP in microemulsions of CTAB. Aggregation kinetics have been measured after 30 min (when aggregation started) under pseudo-first order conditions using $\left[\mathrm{NaBH}_{4}\right]>>\left[\mathrm{AgNO}_{3}\right]$ during the preparation of AgNPs $[24,25,49,50]$. Different $\left[\mathrm{AgNO}_{3}\right]:\left[\mathrm{NaBH}_{4}\right]$ were used to prepare AgNPs and hence to monitor the effect of $\left[\mathrm{NaBH}_{4}\right]$ on aggregation. Fig. 5 shows the rate of aggregation of AgNPs with different $\left[\mathrm{AgNO}_{3}\right]:\left[\mathrm{NaBH}_{4}\right]$ prepared from microemulsions of CTAB $\left(W_{\mathrm{o}}=7.10\right)$.

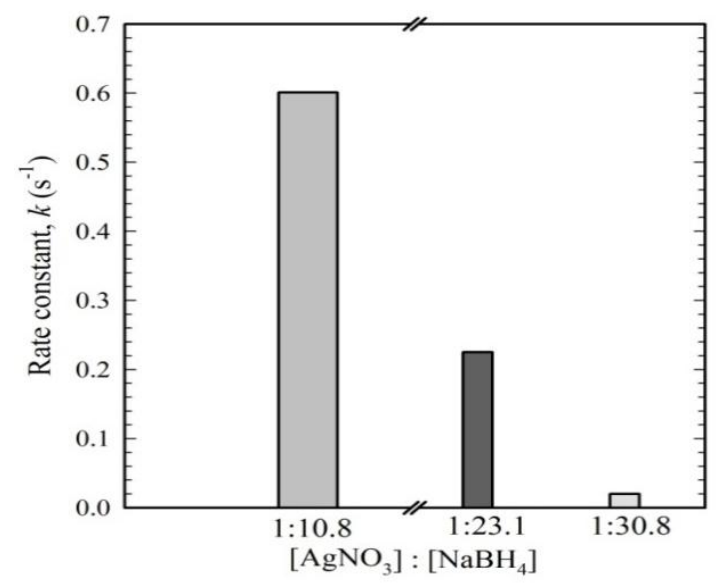

Fig. 5. The rate of aggregation of $\mathrm{AgNPs}$ with different $\left[\mathrm{AgNO}_{3}\right]:\left[\mathrm{NaBH}_{4}\right]$ prepared from microemulsions of CTAB $\left(W_{\mathrm{o}}=7.10\right)$. 
The rate of aggregation of AgNPs decreases with increasing $\left[\mathrm{AgNO}_{3}\right]:\left[\mathrm{NaBH}_{4}\right]$. This corresponds to the change in growth mechanism of AgNPs during preparation with different ratio of $\mathrm{AgNO}_{3}$ with $\mathrm{NaBH}_{4}$. The synthesis of AgNPs by reduction with a strong reductant, like $\mathrm{NaBH}_{4}\left(E_{\mathrm{o}}^{\text {red }}=-0.481 \mathrm{~V}\right.$, [51] $)$ follows a four step growth mechanism proposed by Polte (Fig. 6) [52]. Reduction of $\mathrm{Ag}^{+}$to $\mathrm{Ag}^{0}$ atoms occurs in the first step and different types of clusters like dimers, trimers are formed. Within $\approx 5 \mathrm{~s}$, the clusters coalesce to generate small particles in a second stage; followed by a metastable state, where the particles maintain a constant size for around 5-10 min. A second and last coalescence phase takes place (within 30-60 s) to render the final AgNPs (Fig. 6) [51]. All of these stages are completed within 5-10 min during the formation of AgNPs.

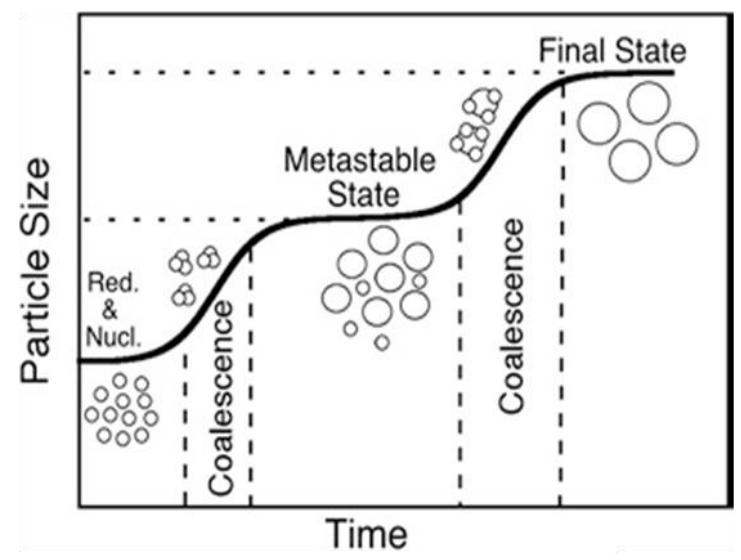

Fig. 6. Four step growth mechanism during the formation of AgNPs synthesized by the reduction of $\mathrm{AgNO}_{3}$ using $\mathrm{NaBH}_{4}$ as reducing agent [52].

Wuithschick et al. studied the metastable state and final coalescence phase by timeresolved SAXS in detail and showed that colloidal stability during the intermediate state is enough to prevent further growth due to particle aggregation [53]. It is well known that each coalescence process implies an aggregation process indicating a decrease in particle stability. The total consumption of $\mathrm{BH}_{4}{ }^{-}$is a triggering event for the initiation of the second coalescence phase due to loss of stability reasonable by oxidation of the metal surface [53]. Although the reaction stoichiometry with $\mathrm{Ag}^{+}$is usually $1: 1, \mathrm{BH}_{4}{ }^{-}$is added in excess. Therefore, the extra $\mathrm{BH}_{4}{ }^{-}$remains in solution helping to stabilize the formed AgNPs (electrostatic stabilization), but it will also begin to hydrolyze decreasing the available $\mathrm{BH}_{4}^{-}$. Hydrolysis is slower compared to the reductive reaction, however, becomes the dominant process once all the $\mathrm{Ag}^{+}$is reduced.

The partial oxidation of the AgNPs surface forming AgO also takes place. The electrostatic stabilization of AgNPs decreases through the presence of these oxides provoking their aggregation. The oxidation of the AgNPs surface can be reversed when there is still $\mathrm{BH}_{4}^{-}$left in solution that avoids the aggregation process. But once all $\mathrm{BH}_{4}{ }^{-}$ ions are consumed, the final coalescence stage commences until the stable size is obtained 
[53].Thus, using a strong reductant, like $\mathrm{NaBH}_{4}$ a faster reduction of $\mathrm{Ag}^{+}$compared to the growth process can be ensured and the growth mechanism is governed by coalescence closely related to the electrostatic stabilization of the AgNPs.

\subsubsection{Effect of $W_{o}$ of microemulsions of CTAB on stability and aggregation}

Stability and aggregation of AgNPs have also been investigated at different $W_{\mathrm{o}}$. The stability increases and the extent of aggregation decreases with increasing $W_{\mathrm{o}}$. AgNPs, prepared from microemulsions of CTAB with $W_{\mathrm{o}}=15.0$ and 20.0 were stable for $\sim 80-85$ min (Fig. 7) while they were stable only for $\sim 30-35$ min prepared from microemulsions of CTAB with $W_{\mathrm{o}}=7.10$ (Fig. 4) for $\left[\mathrm{AgNO}_{3}\right]:\left[\mathrm{NaBH}_{4}\right]=1: 23.1$. In addition, the rate of aggregation of AgNPs is very slow for microemulsions of CTAB with $W_{\mathrm{o}}=15.0$ and 20.0 compared to that of microemulsions of CTAB with $W_{o}=7.10$. This may be due to the fact that with increasing $W_{o}$, the size of core of $W / O$ microemulsions increases [54] by swelling to result in decrease in electrostatic repulsions of surface charge of AgNPs with hydrophillic part, $-\mathrm{N}^{+}\left(\mathrm{CH}_{3}\right)_{3}$ of $\mathrm{CTAB}$. With change in water content in the W/O microemulsions of $\mathrm{CTAB}$, the solubilization capacity of $\mathrm{AgNO}_{3} / \mathrm{NaBH}_{4}$ inside the water droplets of the microemulsion of varying sizes differs and consequently brings about changes in electrostatic repulsions of surface charge of AgNPs with hydrophillic part of CTAB.

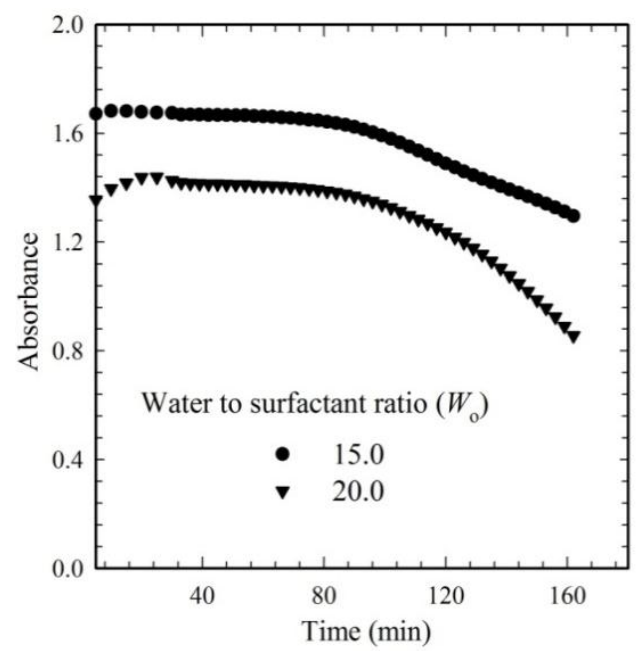

Fig. 7. Absorbance vs. time profile for AgNPs for different $W_{\mathrm{o}}$ in microemulsions of CTAB for $\left[\mathrm{AgNO}_{3}\right]:\left[\mathrm{NaBH}_{4}\right]=1: 23.1$.

In microemulsions with low water content, the electrostatic repulsions between surface charges of AgNPs with hydrophilic part of CTAB are so strong to lower the stability of AgNPs; the AgNPs, containing positive charge in their surface and the hydrophillic part, trimethylammonium ions, $\left(-\mathrm{N}^{+}\left(\mathrm{CH}_{3}\right)_{3}\right)$ of CTAB repels each other as 
well as the AgNPs release from the water droplets and start to aggregate quickly (after 30-35 min). In contrast, microemulsions of high water content having larger water droplets decreases the electrostatic repulsion between positive surface charge of AgNPs and the $-\mathrm{N}^{+}\left(\mathrm{CH}_{3}\right)_{3}$ of CTAB which gives more stability $(\sim 80-85 \mathrm{~min})$ of the AgNPs and aggregation starts very slowly (after $\sim 80-85 \mathrm{~min}$ ) in microemulsions. Thus, high water content in the micremulsion ensures more stable AgNPs and slower aggregation then low water content microemulsions during the preparation of AgNPs.

\subsection{Stability and aggregation of AgNPs in W/O microemulsions of TX-100}

AgNPs have also been prepared from microemulsions of TX-100 to study the influence of nature of surfactants on the formation/aggregation and stability. Fig. 8 represents size distribution (determined from DLS measurements) of AgNPs prepared from microemulsions of TX-100 at different $W_{o}$. The average sizes of AgNPs prepared from micremulsions of TX-100 with $W_{\mathrm{o}}=3.5$ are $\sim 81 \mathrm{~nm}$ (DLS method) while from spectroscopic method this value is $\sim 66 \mathrm{~nm}$ (PWHM). This is due to the fact that DLS measures the sizes of NPs along with the hydrodynamic diameters of microemulsion droplets. It may be worth noting that correlograms (correlation intensity vs time) in the DLS measurements were characteristic of stable species in the system without any sedimentation and aggregation during the course of measurements.

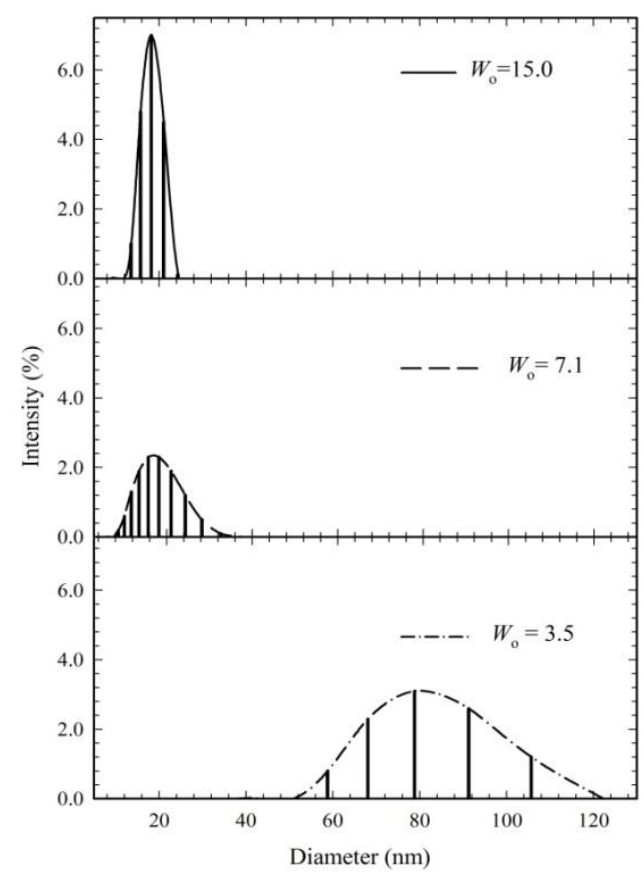

Fig. 8. Size distribution of AgNPs prepared from microemulsions of TX-100 for different $W_{\mathrm{o}}$ by DLS method. 
For all the $W_{\mathrm{o}}$, the size distribution profiles give bimodal distributions with varying sizes of particles. This may be due to the presence of AgNPs and/or aggregated one. Here, the AgNPs with smaller size are only considered for discussion. As the droplet sizes of microemulsions increases with increasing $W_{\mathrm{o}}$ [54], the size of AgNPs also increases. On the other hand, from Fig. 8, surprisingly, it has been found that the average sizes of AgNPs decreases with increases $W_{\mathrm{o}}$ of the microemulsions and give narrower size distribution with higher \%intensity value for $W_{\mathrm{o}}=15.0$. This may be due to the fact that with increasing $W_{0}$, the sizes of water droplets increases in which more reactant species $\left(\mathrm{Ag}^{+}\right.$and $\left.\mathrm{BH}_{4}^{-}\right)$are solubilized into the water core compared to the microemulsions with lower water content. Thus, the AgNPs with smaller sizes may be observed due to faster nucleation and faster reduction [48] for $W_{\mathrm{o}}=15.0$.

Fig. 9 shows the stability and aggregation of AgNPs in W/O microemulsions of TX100 with $\left(W_{\mathrm{o}}=3.50\right)$ for $\left[\mathrm{AgNO}_{3}\right]:\left[\mathrm{NaBH}_{4}\right]=1: 23.1$. After $30 \mathrm{~min}$ stirring, the absorbance still increases with time which is due to either the growth of AgNPs or the increase in the no. of AgNPs. The change in absorbance is almost constant after 1 day with time and indicates the stability of AgNPs. After 3 days, the absorbance decreases very slowly due to the aggregation of AgNPs. Thus, AgNPs prepared from microemulsions of TX-100 are more stable ( 3 days) then the AgNPs prepared from microemulsions of CTAB.

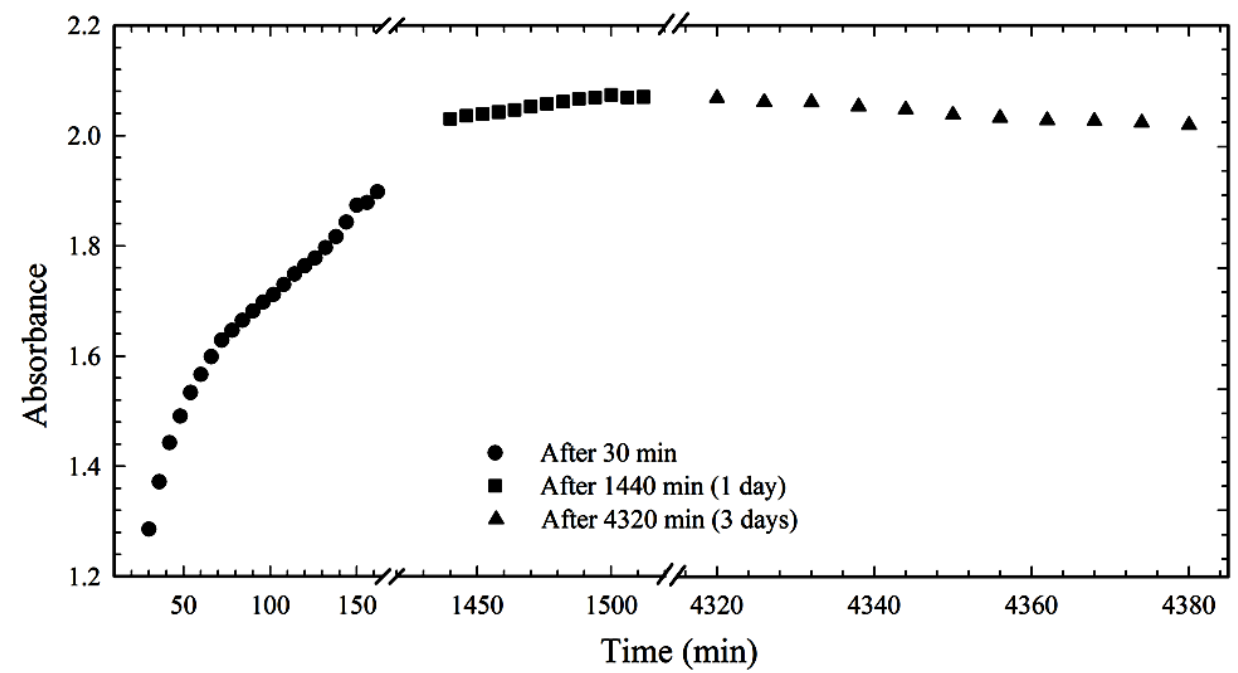

Fig. 9. Absorbance vs. time profile for AgNPs in microemulsions of TX-100 $\left(W_{\mathrm{o}}=3.50\right)$ with $\left[\mathrm{AgNO}_{3}\right]:\left[\mathrm{NaBH}_{4}\right]=1: 23.1$.

\subsection{Role of surfactants in the stabilization of AgNPs}

Interestingly, the surfactants, CTAB and TX-100 play different role in the stabilization of AgNPs (Figs. 4 and 9) for the same $\left[\mathrm{AgNO}_{3}\right]:\left[\mathrm{NaBH}_{4}\right](=1: 23.1)$. Differences in solubilization/incorporation of reactant species and/or AgNPs into water droplets and adsorption of AgNPs on the surface of CTAB and TX-100 microemulsion or release of 
AgNPs into the bulk make the difference. Scheme 1 shows the stabilization mechanisms of AgNPs prepared from microemulsions of CTAB (a) and TX-100 (b).

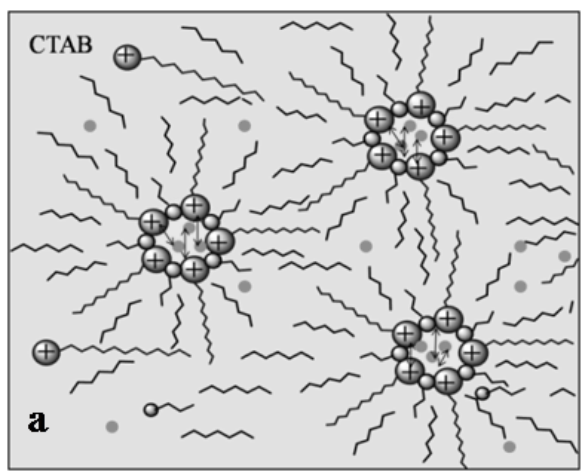

(a) Repulsion of cationic trimethylammonium groups of $\mathrm{CTAB}$ with surface charge on AgNPs.

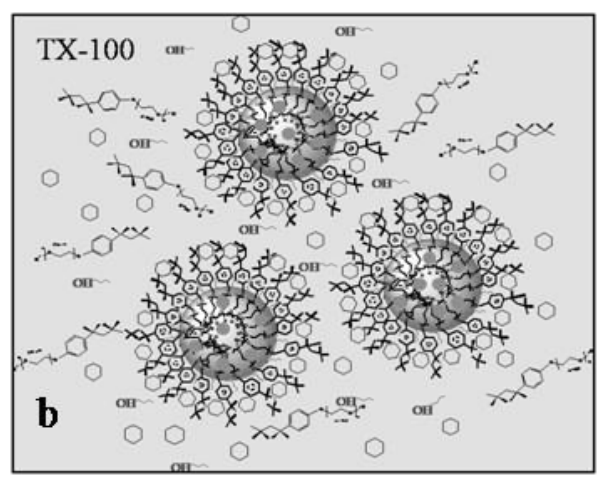

(b) AgNPs are stabilized by nonionic oxyethylene groups of TX-100.

Scheme 1. The stabilization mechanisms of AgNPs prepared from microemulsions of CTAB (a) and TX-100 (b).

It is well-known that microemulsions can change the rates, pathway of chemical reactions etc. by virtue of their medium effect due to the incorporation and/or solubilization of reactants into the small volume of water droplets through hydrophobic, electrostatic, hydrogen bonding and Van der Waals forces [55-57]. The presence of positive charge on $\mathrm{Ag}^{+}$and $\mathrm{AgNPs}$ must be considered to explain the different behavior of water droplets in $\mathrm{CTAB}$ and TX-100 microemulsions. In microemulsions of $\mathrm{CTAB}, \mathrm{Ag}^{+}$ and $\mathrm{BH}_{4}^{-}$are expected to be mainly in the oil phase and micellar pseudophases, respectively due to electrostatic repulsion and interaction between $\mathrm{Ag}^{+}$and $\mathrm{BH}_{4}^{-}$with positive $-\mathrm{N}^{+}\left(\mathrm{CH}_{3}\right)_{3}$ of CTAB micelles, respectively. On the other hand, AgNPs stabilized by hydrophilic oxyethylene groups of $\mathrm{TX}-100$ correspond to the steric as well as hydrophobic interactions in water droplets of microemulsions [50]. One key factor is the reaction rate which is faster in presence of CTAB than that of TX-100. Aggregation of AgNPs in microemulsions of TX-100 is much slower than that of CTAB due to the fact that the sterically and hydrophobically stabilized AgNPs may be more resistant to aggregation compared to the electrostatically stabilized AgNPs [50]. Thus, the extent of the stability of AgNPs having the same stabilization mechanisms may differ.

\section{Conclusions}

Stability and aggregation can be controlled by using microemulsions with proper choice of surfactants as templates for preparation of AgNPs. In microemulsions of CTAB, with increasing the concentration of $\mathrm{AgNO}_{3}$, the number of AgNPs increases. On the contrary, AgNPs prepared from CTAB microemulsions are unstable and precipitate out into the 
bulk and aggregate depending on the concentration of $\mathrm{AgNO}_{3}$. With increasing the ratio of $\mathrm{AgNO}_{3}$ and $\mathrm{NaBH}_{4}$, stability of AgNPs prepared from microemulsions of CTAB remains constant ( 30-35 $\mathrm{min})$; however the rate of aggregation decreases. With change in water to surfactant ratio of CTAB microemulsions, stability of AgNPs can be increased up to 80-85 min. Silver nanoparticles prepared from TX-100 are more stable ( 3 days) than that of CTAB. In addition, aggregation occurs very slowly in TX-100 compared to CTAB. Thus, a suitable surfactant, compositions, ratio of $\mathrm{AgNO}_{3}$ and $\mathrm{NaBH}_{4}$ or time is essential for the production of stable silver nanoparticles.

\section{Acknowledgment}

The authors acknowledge financial support from Higher Education Quality Enhancement Project under the Sub-project, CPSF-231 from Bangladesh University Grants Commission financed by World Bank and the Ministry of Education, Bangladesh. FB also acknowledges Bangladesh Council of Scientific and Industrial Research (BCSIR) Dhaka, Bangladesh for financial support through Post-Doctoral Fellowship.

\section{References}

1. K. N. Thakkar, S. S. Mhatrem, and R.Y. Parikh, Nanomed. NBM 6, 257 (2010). https://doi.org/10.1016/j.nano.2009.07.002

2. P. Kouvaris, A. Delimitis, V. Zaspalis, D. Papadopoulos, S. Tsipas, and N. Michailidis, Mater. Lett. 76, 18 (2012). https://doi.org/10.1016/j.matlet.2012.02.025

3. K. Shameli, M. B. Ahmad, E. A. J. Al-Mulla, N. A. Ibrahim, P. Shabanzadeh, A. Rustaiyan, Y. Abdollahi, S. Bagheri, S. Abdolmohammadi, M. S. Usman, and M. Zidan, Molecules 17, 8506 (2012). https://doi.org/10.3390/molecules17078506

4. S. Hussain and A. K. Pal, Mater. Lett. 62, 1874 (2008). https://doi.org/10.1016/j.matlet.2007.10.021

5. S. Parveen, R. Misra, and S. K. Sahoo, Nanomedicine 8, 147 (2012). https://doi.org/10.1016/j.nano.2011.05.016

6. S. Gurunathan, K. V. Kalishwaralal, R. Aidyanathan, V. Deepak, S. Pandian, and J. Muniyandi, Colloids Surf. B 74, 328 (2009). https://doi.org/10.1016/j.colsurfb.2009.07.048

7. A. Ahmad, P. Mukherjee, S. Senapati, D. Mandal, M. Islam Khan, R. Kumar and M. Sastry, Colloids Surf. B 28, 313 (2003). https://doi.org/10.1016/S0927-7765(02)00174-1

8. W. R. Hill, D. M. Pillsbury, Argyria: The Pharmacology of Silver, Baltimore. (Md. Williams and Wilkins Co, 1939) pp. 128

9. J. T. Lue, Phys. Chem. Solids 62, 1599 (2001).https://doi.org/10.1016/S0022-3697(01)00099-3

10. M. Rai, A. Yadav, and A. Gade, Biotechnol. Adv. 27, 76 (2009). https://doi.org/10.1016/j.biotechadv.2008.09.002

11. J. Fabrega, S. N. Luoma, C. R. Tyler, T. S. Galloway, and J. R. Lead, Environ. Int. 37, 517 (2011). https://doi.org/10.1016/j.envint.2010.10.012

12. A. Lapresta-Fernandez, A. Fernandez, and J. Blasco, TrAC Trends Anal. Chem. 32, 40, (2012).

13. M. Auffan, J. Y. Bottero, C. Chaneac and J. Rose, Nanomedicine UK 5, 999 (2010). https://doi.org/10.2217/nnm.10.61

14. A. P. Gondikas, A. Morris, B. C. Reinsch, S. M. Marinakos, G. V. Lowry, and H. Hsu-Kim, Environ. Sci. Technol. 46, 7037 (2012). https://doi.org/10.1021/es3001757

15. C. Levard, E. M., Hotze, G. V. Lowry, and G. E. Brown, Environ. Sci. Technol. 46, 6900 (2012). https://doi.org/10.1021/es2037405 
16. B. J. R. Thio, M. O. Montes, M. A. Mahmoud, D.-W. Lee, D. Zhou, and A. A. Keller, Environ. Sci. Technol. 46, 6985 (2011). https://doi.org/10.1021/es203596w

17. S. D. Solomon, M. Bahadory, A. V. Jeyarajasingam, S. A. Rutkowsky, and C. Boritz, J. Chem. Educ. 84, 322 (2007). https://doi.org/10.1021/ed084p322

18. F. P. Mehr, M. Khanjani, and P. Vatani, Orient. J. Chem. 31, 1831 (2015). https://doi.org/10.13005/ojc/310367

19. B. Khodashenas and H. R. Ghorbani, Arab. J. Chem. (2015). https://doi.org/10.1016/j.arabjc.2014.12.014

20. H. Wang, X. Qiao, J. Chena, and S. Ding, Colloids Surf. A Physicochem. Eng. Asp. 256, 111 (2005). https://doi.org/10.1016/j.colsurfa.2004.09.037

21. K. Mavani and M. Shah, Int. J. Adv. Res. Technol. 2, 1 (2013).

22. K. Esumi, T. Hosoya, A. Suzuki, and K. Torigoe, J. Colloid Interface Sci. 226, 346 (2000). https://doi.org/10.1006/jcis.2000.6849

23. Z. Khan, S. A. Al-Thabaiti, A. Y. Obaid, and A. O. Al-Youbi, Colloids Surf. B Biointerfaces 82, 513 (2011). https://doi.org/10.1016/j.colsurfb.2010.10.008

24. J. I. Hussain, S. Kumar, A. A. Hashmi and Z. Khan, Adv. Mat. Lett. 2, 188 (2011). https://doi.org/10.5185/amlett.2011.1206

25. S. A. Al-Thabaiti, F. M. Al-Nowaiser, A. Y. Obaid, A. O. Al-Youbi, and Z. Khan, Colloids Surf. B Biointerfaces 67, 230 (2008). https://doi.org/10.1016/j.colsurfb.2008.08.022

26. Z. Khan and A. Talib, Colloids Surf. B Biointerfaces 76, 164 (2010). https://doi.org/10.1016/j.colsurfb.2009.10.029

27. Y. Xie, R. Ye, and H. Liu, Colloids Surf. A Physicochem. Eng. Asp. 279, 175 (2006). https://doi.org/10.1016/j.colsurfa.2005.12.056

28. A. E. Hart, D. B. Akers, S. Gorosh, and C. L. Kitchens, J. Supercrit. Fluids 79, 236 (2013). https://doi.org/10.1016/j.supflu.2013.02.014

29. P. Setua, R. Pramanik, S. Sarkar, C. Ghatak, S. K. Das, and N. Sarkar, J. Phys. Chem. B 114, 7557 (2010). https://doi.org/10.1021/jp1008048

30. A. Taleb, C. Petit and M. P. Pileni, Chem. Mater. 9, 950 (1997). https://doi.org/10.1021/cm960513y

31. T. T. N. Dung, N. Q. Buu, D. V. Quang, H. T. Ha, L. A. Bang, N. H. Chau, N. T. Ly, and N. V. Trung, J. Phys. Conf. Ser. 187, 012054 (2009). https://doi.org/10.1088/1742-6596/187/1/012036

32. H. Noritomi, Y. Umezawa, S. Miyagawa, and S. Kato, Adv. Chem. Eng. Sci. 1, 299 (2011). https://doi.org/10.4236/aces.2011.14041

33. W. Zhang, X. Qiao, and J. Chen, Mater. Sci. Eng. B 142, 1 (2007). https://doi.org/10.1016/j.mseb.2007.06.014

34. S. S. Satter, M. Hoque, M. M. Rahman, and M. Y. A. Mollah, RSC Adv. 14, 20612 (2014).

35. S. Hossain, U. K. Fatema, M.Y.A. Mollah, M. M. Rahman, and M. A. B. H. Susan, J. Bang. Chem. Soc. 25, 71 (2012).

36. J. N. Solanki and Z. V. P. Murthy, Ind. Eng. Chem. Res. 50, 12311 (2011). https://doi.org/10.1021/ie201649x

37. A. Ledo, F. Martinez, M.A. Lopez-Quintela, and J. Rivas, Physica B 398, 273 (2007). https://doi.org/10.1016/i.physb.2007.05.010

38. P. Y. Reyes, J A. Espinoza, M. E. Treviño, H. Saade, and R. G. López, J. Nanomater. 2010, 1 (2010). https://doi.org/10.1155/2010/948941

39. Y. D. Sosa, M. Rabelero, M. E. Treviño, H. Saade, and R. G. López, J. Nanomater. 2010, 1 (2010). https://doi.org/10.1155/2010/915937

40. V. K. Sharma, K. M. Siskova, R., Zboril, and J. L. Gardea-Torresdey, Adv. Colloid Interface Sci. 204, 15 (2014). https://doi.org/10.1016/j.cis.2013.12.002

41. M. Baalousha, M. N. Croteau, K. Dawson, E. S. Goldberg, W. How, F. R. Khan, J. Lead, S. M. Louie, G. V. Lowry, S. N. Luoma, I. Lynch, R. Ma, A. Praetorious, M. Scheringer, K. Schirmer and E. Valsami-Jones, Nanoscience and the Environment. 1st edition (Elsevier, 2014). 
42. Z. Y. Huang, G. Mills, and B. J. Hajek, Phys. Chem. 97, 11542 (1993). https://doi.org/10.1021/j100139a025

43. C. Burda, X. Chen, R. Narayanan, and M. A. El-Sayed, Chem. Rev. 105, 1025 (2005). https://doi.org/10.1021/cr030063a

44. L. M. Liz-Marzan, Langmuir 22, 32 (2006). https://doi.org/10.1021/la0513353

45. P. K. Khanna, N. Singh, S. Charan, V. V. V. S. Subbarao, R. Gokhale, and U. P. Mulik, Mater. Chem. Phys. 93, 117 (2005). https://doi.org/10.1016/j.matchemphys.2005.02.029

46. E. M. Egorova, Russ. J. Phys. Chem. A 84, 629 (2010). https://doi.org/10.1134/S0036024410040199

47. Z. Yunxia, L. Tielong, J. Zhaohui, W. Wei, and W. Shuaima, Front. Environ. Sci. Eng. China 1, 466 (2007). https://doi.org/10.1007/s11783-007-0074-5

48. A. Sobczak-Kupiec, D. Malina, Z. Wzorek, and M. Zimowska, Micro. Nano. Lett. 6, 656 (2011). https://doi.org/10.1049/mnl.2011.0152

49. Xuan Li, John J. Lenhart, and H. W. Walker, Langmuir 26, 16690 (2010). https://doi.org/10.1021/la1034432

50. A. M. E Badawy, K. G. Scheckel, M. Suidan, and T. Tolaymat, Sci. Total Environ. 429, 325 (2012). https://doi.org/10.1016/j.scitotenv.2012.03.041

51. P. Vanysek, Electrochemical Series, ed. D. R. Lide, In: CRC Handbook of Chemistry and Physics (CRC Press, LLC, 2003-2004) pp. 8.21-8.31.

52. J. Polte, X. Tuaev, M. Wuithschick, A. Fischer, A. F. Thuenemann, K. Rademann, R. Kraehnert, and F. Emmerling, ACS Nano 6, 5791 (2012). https://doi.org/10.1021/nn301724z

53. M. Wuithschick, B. Paul, R. Bienert, A. Sarfraz, U. Vainio, M. Sztucki, R. Kraehnert, P. Strasser, K. Rademann, F. Emmerling, and J. Polte, Chem. Mater. 25, 4679, (2013). https://doi.org/10.1021/cm401851g

54. S. Sultana, S. Saha, M. M. Islam, M. M. Rahman, M. Y. A. Mollah, and M. A. B. H. Susan, J. Electrochem. Soc. 160, 524 (2013). https://doi.org/10.1149/2.039311jes

55. C.A. Bunton and G. Savelli, Adv. Phys. Org. Chem. 22, 213 (1986). https://doi.org/10.1016/S0065-3160(08)60169-0

56. S. Tascioglu, Tetrahedron 52, 11113 (1996). https://doi.org/10.1016/0040-4020(96)00669-2

57. C. A. Bunton, J. Mol. Liq. 72, 231 (1997). https://doi.org/10.1016/S0167-7322(97)00040-8 